\title{
Study on Mode I fatigue behaviour of Nylon 6,6 nanoreinforced CFRP laminates
}

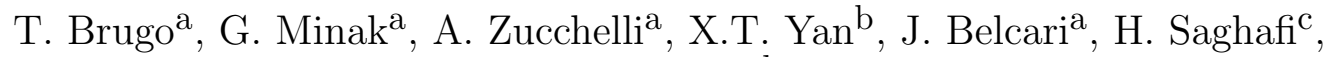 \\ R. Palazzetti ${ }^{\mathrm{b}, *}$ \\ ${ }^{a}$ University of Bologna, Department of Industrial Engineering, viale del Risorgimento 2, \\ 40136 Bologna, Italy \\ ${ }^{b}$ University of Strathclyde, DMEM department, 75 Montrose Street, G1 1XJ, Glasgow, \\ $U K$ \\ ${ }^{c}$ Amirkabir University of Technology, Polymer Engineering Department, 424 Hafez Ave, \\ 15914, Tehran, Iran
}

\begin{abstract}
The benefits of interleaving polymeric electrospun nanofibers in between laminae of composite structure have been widely demonstrated in the past several years. Among the work that still has to be done, this paper aims to study delamination propagation of virgin and nanomodified specimens under Mode I fatigue loading. A 40-micron thick layer of Nylon 6,6 nanofibers have been produced and interleaved in carbon fiber-epoxy resin composite laminates; static and dynamic double cantilever tests have been performed to determine delamination growth onset and crack propagation rate vs. maximum energy release rate respectively.

Nanomodified specimens exhibited improved delamination resistance during both the tests: delamination toughness increased $130 \%$ and cracks propagated 36 to 27 times slower than virgin interfaces.

The benefits of the nanointerleave and its working mechanism have been explained using micrographs and SEM images, which revealed a double-stage reinforce mechanism.
\end{abstract}

Keywords: Fatigue, Delamination, Composite Material, Crack Grow

\footnotetext{
${ }^{*}$ Principal corresponding author

Email addresses: tommasomaria.brugo@unibo.it (T. Brugo), giangiacomo.minak@unibo.it (G. Minak), a.zucchelli@unibo.it (A. Zucchelli), x.yan@strath.ac.uk (X.T. Yan), juri.belcari2@unibo.it (J. Belcari), hsaghafi@aut.ac.ir (H. Saghafi), roberto.palazzetti@strath.ac.uk (R. Palazzetti)
} 
Ratio, Nanofibers

\section{Introduction}

Composite laminates are the latest game-changer in popular engineering materials, and researchers have widely investigated them in the last few decades, with particular focus on delamination [1], caused by excessive stain or interlaminar stress. Delamination is the main failure modes for composite laminates which can suffer up to $60 \%$ reduction in stiffness and still remain visibly unchanged [2]. Researchers proposed several solutions to solve or mitigate delamination-related problems [3-9]. Carbon nanofibers/nanotubes (CNFs/CNTs) proved to be the most effective solution in terms of mechanical reinforcement [10-12], but their difficult mixing process with the resin [13] and serious risks for human health [14] make them unsuitable in many cases.

Polymers present several advantages compared to CNF/CNT, and the authors of present paper have a successful history of reinforcing composite laminates' interfaces using polymeric nanofibers [15-18], in particular Nylon 6,6 [19-23].

The academic community produced accurate research on nanomodified composites, but some aspects still need to be further investigated: in particular this paper aims to study nanointerleaved laminates subjected to cycling loads, which is a topic for only few papers can be found in literature [10$12,24]$.

Bortz et al. [10] performed axial fatigue tests (tension, compression, tension dominated) on carbon nanofibers interleaved composites, showing for nanomodified samples 150-670\% longer lifetime. They addressed their results to an increased interface density and to the damage shielding effect of the reinforce. Arai et el. [11] also used carbon nanoreinforce, in their case multi-walled carbon nanotubes (MWCNT), and measured propagation rate during Mode I fatigue tests. Their results show that the nanomodified interfaces extended the fatigue life and fracture toughness by 150 and 300\% respectively. Similar results have been found by Zhou et al. [12] in both static and fatigue tests.

Shivakumar et al. [24] used Nylon 6,6 to produce nanofibers instead of carbon, and performed a deep investigation on the effect of the nanointerleave on uni-directional (UD) laminates under different loading conditions. On the 
fatigue side, they showed a significant increase on delamination onset life for nanomodified specimens.

Brugo et al. [16], as per author's best knowledge, present the only other work in literature on fatigue behaviour of woven composite laminate reinforced with nanofibers. Their results show a different behavior of fatigue delamination propagation from that shown in [24], due to the fact that in UD laminates the crack may propagate through plies, which can not happen in woven laminates due to the textile of the fabric. Furthermore, [16] showed fatigue curves with the typical asymptotic trend of fatigue tests and the fiber bridging was confined by the waviness nature of the laminate's tow.

However, whilst the fatigue behavior at the onset of the delamination of nanointerleaved laminates has been already investigated, there is lack of research on the effect of nanofibrous interleaves on crack propagation rate.

Present study aims to investigate the effect of interleaving electrospun Nylon 6,6 nanofibers in epoxy-based carbon fiber woven composite materials, tested under Mode I fatigue loading. The purpose is to assess the constant crack growth rate section of the Paris law diagrams for virgin $(V)$ and nanomodified $(N)$ specimens. Static double cantilever beam (DCB) tests have been also performed in order to determine the fracture toughness of the material at crack initiation and propagation.

Results showed that nanomodified specimens present a significantly slower crack propagation rate than virgin samples under similar loading conditions. Micrographs of the crack path and Scanning Electron Microscope (SEM) images of the crack surfaces have been used to investigate the nanofibrous reinforce mechanism.

\section{Materials and methods}

\subsection{Sample preparation}

The international standard ASTM D5528 [26] has been used as reference for DCB specimen dimensions: 14 layers of $375 \mathrm{~g} / \mathrm{m}^{2}$ plain wave carbonepoxy prepreg (GG204P-IMP503Z) supplied by Impregnatex Compositi Srl (Milan, Italy) have been stacked to manufacture 130x20 $\mathrm{mm}^{2}$ specimens, with an initial crack a of $45 \mathrm{~mm}$ long artificially created by interleaving a $30 \mu \mathrm{m}$ thick PTFE film in the mid-interface. Nanofibers of Nylon 6,6 Zytel E53NC010 purchased from DuPont have been produced by electrospinning following the process detailed in [16]. The final nanointerleaves had areal

density of $18 \mathrm{~g} / \mathrm{m}^{2}$, and were $40 \mu \mathrm{m}$ thick; randomly distributed nanofibers 
had diameter of $520 \pm 100 \mathrm{~nm}$. $N$ specimen had a nanofibrous layer in the mid interface. Post-processing and interleaving have been done following the procedures presented in [16].

Final laminates' thickness was $3.5 \pm 0.1 \mathrm{~mm}$ with no appreciable differences between $V$ and $N$ configurations. The estimated increase of weight for $N$ samples was $0.34 \%$

The cure cycle presented in [16] has been followed.

Figure 1 shows $V$ and $N$ interfaces at a magnitude of 5000x: nanofibers in $N$ samples are clearly visible and intact, after the curing cycle.
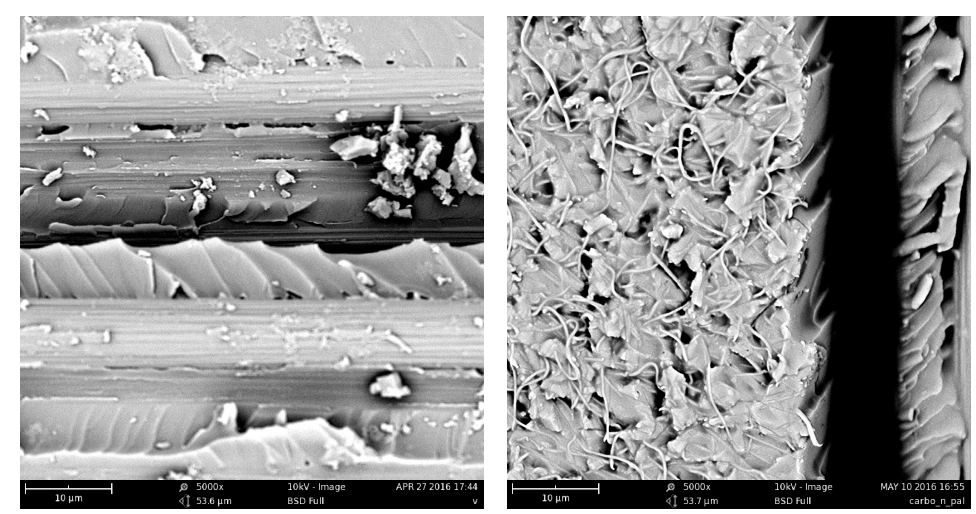

Figure 1: $V$ (left) and $N$ (right) interfaces

\subsection{Static Test}

Static DCB tests have been performed in order to calculate fracture toughness at crack initiation $\left(\mathrm{G}_{\mathrm{C}}\right)$ and propagation $\left(\mathrm{G}_{\mathrm{R}}\right)$. The Modified Beam Theory (MBT) [26] has been used and the Equation (1) was applied.

$$
\mathrm{G}=\frac{3 \mathrm{~F} \delta}{2 \mathrm{Ba}}
$$

where $\mathrm{F}$ is the force, $\delta$ the crack opening displacement, $\mathrm{B}$ the specimen width, and a the crack length.

Static test's conditions and results have been already presented in [16], and have also been summarised here because the present experimental campaign is directly affected by those results.

\subsection{Fatigue tests}

In order to evaluate the reinforce effect of the here developed nanofibers, authors consider enough performing three tests for each configuration. This 
assumption has been confirmed valid by the narrow error margin of the experiments compared to the data range of experiments (see Figure 4).

In order to create a sharp naturally induced crack, the specimens have been fatigue pre-cracked (loading ratio $\mathrm{R}\left(\delta_{\min } / \delta_{\max }\right)$ equal to $0.3, \mathrm{G}_{\max }=$ $\left.50 \% \mathrm{G}_{\mathrm{C}}\right)$ until the artificial crack propagated $1 \mathrm{~mm}$.

The imposed displacement limits of the fatigue tests have been set on the basis of the results of the static tests. Having the static and fatigue specimens the same configuration, using the beam theory, the crack opening displacement is obtained by the ratio between the desired initial $\mathrm{G}_{\max , 0}$ and the statics $\mathrm{G}_{\mathrm{C}}$. The formula is shown in Equation (2):

$$
\delta_{\max }=\sqrt{\frac{\mathrm{G}_{\max , 0}}{\mathrm{G}_{\mathrm{C}}}}\left(\frac{\mathrm{a}_{0}}{\mathrm{a}_{\mathrm{C}}}\right)^{2} \delta_{\mathrm{C}}
$$

where $\delta_{\max }$ is the maximum crack opening displacement, $G_{\max , 0}$ is the $\mathrm{G}$ at which the tests started, a $\mathrm{a}_{0}$ is the initial crack length, and ${ }^{a_{\mathrm{C}}}$ and ${ }{ }_{\mathrm{C}}$ are the critical crack length and crack opening displacement respectively, determined from the static tests. $\mathrm{G}_{\max , 0} / \mathrm{G}_{\mathrm{C}}$ has been set equal to 0.85 , following other authors' experience [27]; this allows to speed-up and record the complete behaviour of crack propagation [28]. Different values of $\delta_{\max }$ have been calculated for each configuration due to different values of $\mathrm{G}_{\mathrm{C}}$ for $V$ and $N$ specimens.

The aim of the paper is to determine the crack grow ratio of nanointerleaved composites, for an international standard does not exist. Authors used the international standard ASTM D6115 [29] for fatigue delamination growth onset for composite laminates, and the ASTM E647-15 [30] for the fatigue crack growth rates for homogeneous materials. The tests have been conduced under displacement control, at a load frequency of $3 \mathrm{Kz}$ to avoid any heating, with a loading ratio $\mathrm{R}$ equal to 0.3 , for $500 \mathrm{k}$ cycles. A uniball-like gripper avoided any undesired in-plane loads.

Outcome of the dynamic experiments were the da/dN vs. $\mathrm{G}_{\max }$ curves for $V$ and $N$ configurations. a is the crack length, da/dN the crack propagation rate, and $\mathrm{G}_{\max }$ the energy release rate of the material calculated at the peak load of each cycle.

Researchers have debated the use of $\mathrm{G}_{\max }, \mathrm{G}_{\min }, \Delta \mathrm{G}$ or $\Delta \sqrt{\mathrm{G}}$ for fatigue tests of composites [31]. In the cycle range here considered $\left(\mathrm{N}<10^{6}\right)$, for investigating the effect of interleaved nanoreinforce, $\mathrm{G}_{\max }$ is the most appropriate choice. 
For each cycle maximum and minimum load and displacement were registered; crack length was measured with a resolution of $0.5 \mathrm{~mm}$ during the test by an high-resolution camera facing the side of the specimens.

\subsection{Methodology}

The crack propagation rate curves were determined based on compliance (C) method proposed in [32]. The compliance is the inverse of the stiffness and has been calculated at each cycle using Equation (3).

$$
\mathrm{C}=\frac{\delta_{\max }-\delta_{\min }}{\mathrm{F}_{\max }-\mathrm{F}_{\min }}
$$

where max and min identify the peak and the valley of the cycle.

Images of the crack length were collected throughout the experiment on a logarithmic base: one photograph at each cycle for the first 10 cycles; one photograph every 10 cycles within the following 100 cycles; one photograph every 100 cycles within the following 1000 cycles; one photograph every 1000 cycles for the following 10000 cycles; finally a photograph every 10000 cycles until the end of the test.

The relation between the specimen compliance and the crack length has been derived based on the Eulero-Bernulli beam theory [33] and is shown in Equation (4):

$$
\mathrm{a} / 2 \mathrm{H}=\alpha_{0}+\alpha_{1}(\mathrm{BC})^{1 / 3}
$$

where $2 \mathrm{H}$ and $\mathrm{B}$ are the sample thickness and width, respectively, and $\alpha_{0}$ and $\alpha_{1}$ are fitting coefficients function of the elastic modulus of the laminate. Each photograph, and therefore each crack length, were related with the corresponding compliance to build the a/2H vs $(B C)^{1 / 3}$ chart. $\alpha_{0}$ and $\alpha_{1}$ coefficients for each specimen were obtained by linear regression. The crack length at each cycle has been determined by reversing Equation (4).

$\mathrm{da} / \mathrm{dN}$ throughout the tests is evaluated through centered moving average and the result is plotted in Figure 2a.

The energy release rate calculated at the peak value of each cycle $\left(G_{\max }\right)$ is determined using Equation (1). Results are reported in Figure 2b. 


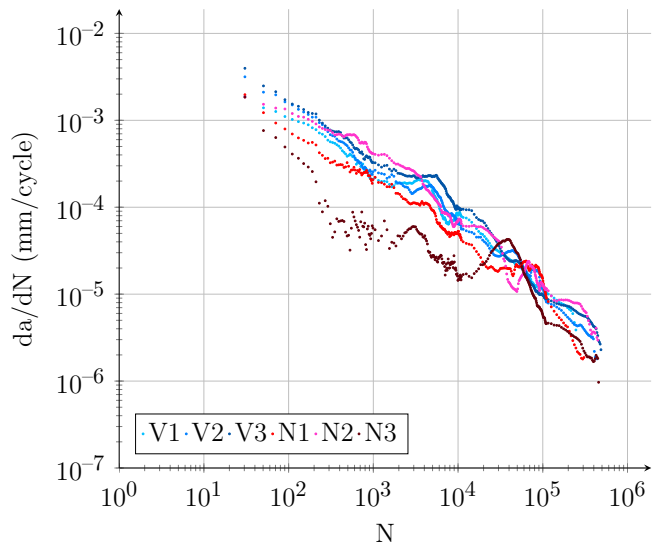

(a) da/dN $(\mathrm{N})$

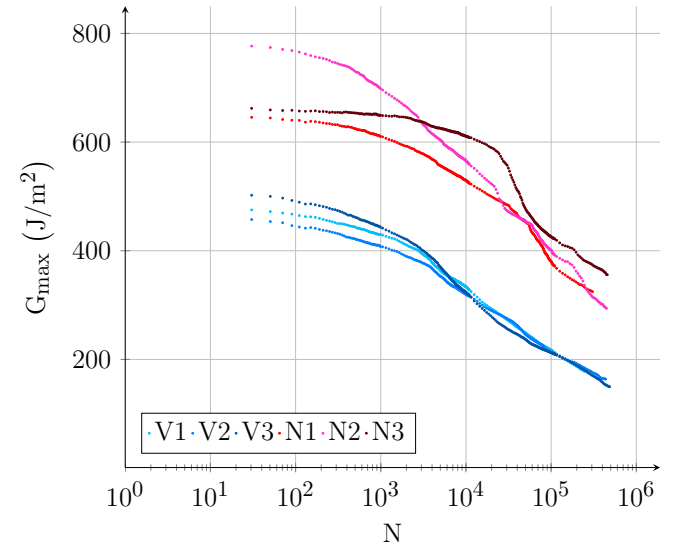

(b) $\mathrm{G}_{\max }(\mathrm{N})$

Figure 2: Crack grow ratio and $\mathrm{G}_{\max }$ vs N. 1, 2, and 3 identify specimen number

By combining the last two graphs, the da/dN vs $\mathrm{G}_{\max }$ plots can be assembled.

It is worth mentioning that data has been filtered two times during the process in order to gain smoother results. Data have been divided into 4 groups: group I data from $\mathrm{N} \leq 10^{3}$; group II data from $10^{3}<\mathrm{N} \leq 10^{4}$; group III data from $10^{4}<\mathrm{N} \leq 10^{5}$; group 4 data from $\mathrm{N}>10^{5}$. Compliance and crack length have been evaluated at each cycle and then filtered and reduced using moving centered average with variable span (20,100, 1000, 10000 for group I, II, III and IV, respectively). da/dN was then calculated by discrete centered derivation and filtered by a moving centered average with a span of 20 .

\section{Results and discussion}

\subsection{Static tests}

Figure 3 summarises the results of the static tests. Force-Displacement curves for each specimen and the resultant R-Curves for each configuration are shown in Figure 3a and 3b, respectively. 


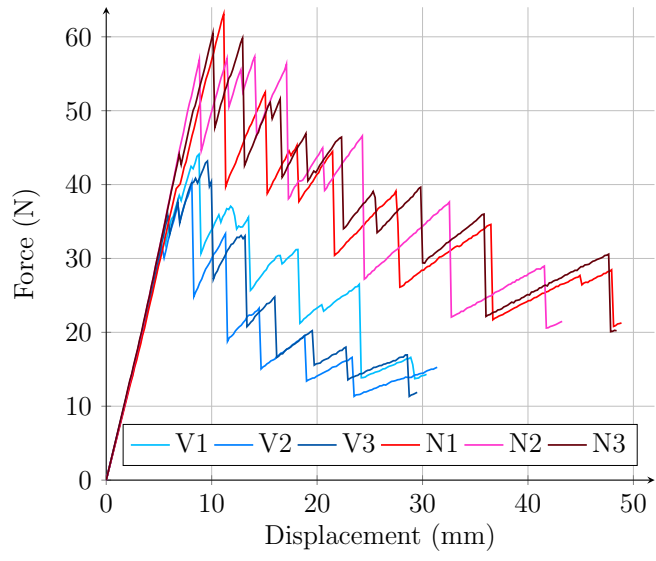

(a) Static force-displacement curves

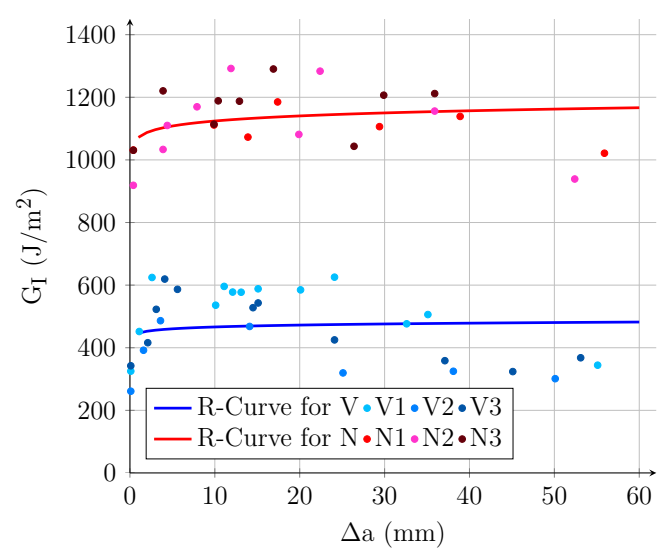

(b) Static R curves

Figure 3: Static test results. 1, 2, and 3 identify specimen number

The complete set of static tests results have been already presented and discussed in [16], showing a significant improvement in force and energy release rate due to interleaved nanofibers. The fracture toughness is increased at both crack initiation and propagation ( $137 \%$ and $124 \%$, respectively), and the crack propagates stably for longer than $50 \mathrm{~mm}$, as shown by the RCurves in Figure 3b. The nanofibers' toughening effect is also detected at crack propagation, anticipating improvement of performances under fatigue loading, where the crack propagates for longer than $10 \mathrm{~mm}$. As observed in [16], the same is not possible in UD laminate, for the crack diverges from the toughened interlayer. Moreover, the static $G_{C}$ values have been used into Equation (2) to set-up fatigue test parameters.

\subsection{Fatigue tests}

The log-log plot in Figure 4 shows the crack propagation rate vs. maximum energy release rate outcome of the fatigue tests, determined with the method proposed above for each specimen. 


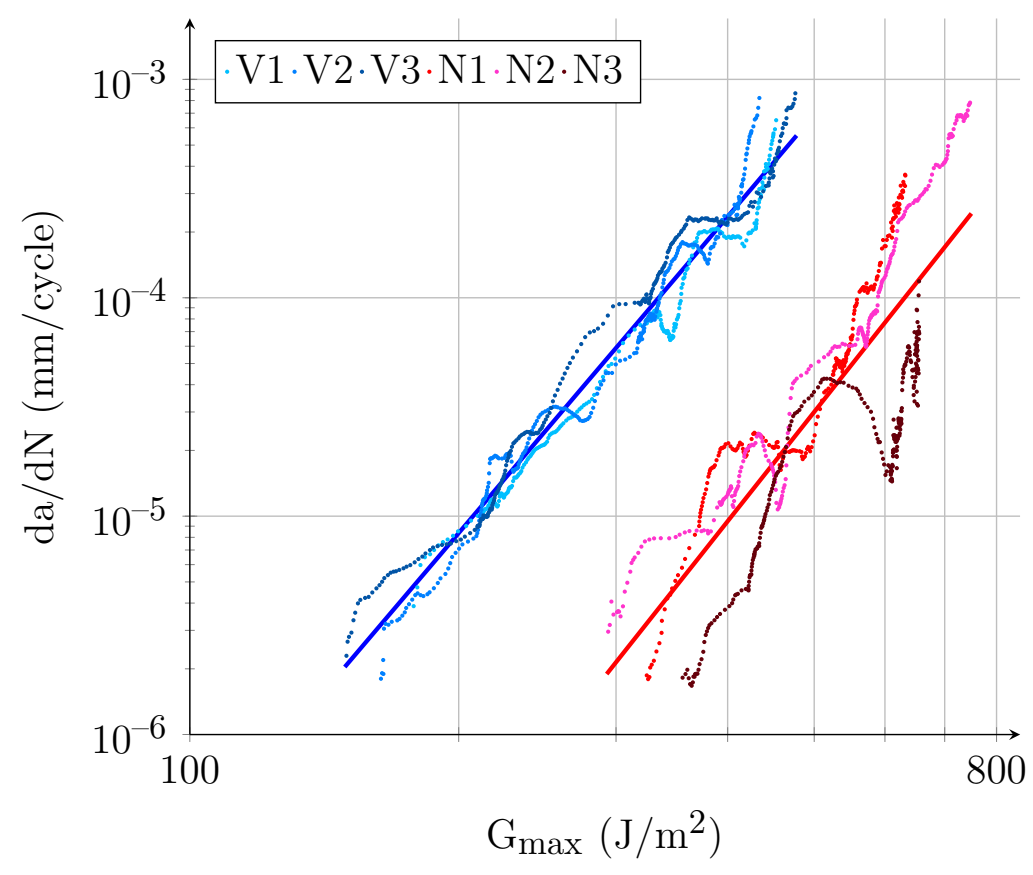

Figure 4: da/dN vs. $\mathrm{G}_{\max }$ plots for $V$ and $N$ specimens

The straight lines in Figure 4 represent the stable-growth propagation phase of the Paris law and are obtained by a a linear interpolation of the da/dN vs. $\mathrm{G}_{\max }$ scatters in a log-log plot. Those lines, straight in the log-log plot, would be power laws in a linear-linear plot, shown in the form shown in Equation (5) [34].

$$
\frac{\mathrm{da}}{\mathrm{dN}}=\mathrm{A} \cdot \mathrm{G}_{\max }{ }^{\mathrm{n}}
$$

where $\mathrm{A}$ and $\mathrm{n}$ are determined by the curve fitting of the experimental data, and have still unclear physical meaning [31].

The figure shows that for a given stress $\mathrm{G}_{\max }$, cracks in nanomodified interfaces propagates slower than in virgin samples, and that to keep the crack propagation below a threshold level, nanomodified samples can be loaded with higher stress.

As example, for da/dN $=5 \cdot 10^{-5} \mathrm{~mm} /$ cycle, $V$ and $N$ can be loaded with 287 and $565 \mathrm{~J} / \mathrm{m}^{2}$, respectively, showing that the $N$ load almost doubles that of $V$ samples. In the da/dN range in common between the two configuration, $N$ samples can be loaded with $46-55 \%$ higher load. 
Focusing on solicitation, at a $\mathrm{G}_{\max }=400 \mathrm{~J} / \mathrm{m}^{2}$, the crack propagation rates are $2.4 \cdot 10^{-4}$ and $7.9 \cdot 10^{-6} \mathrm{~mm} /$ cycle for $V$ and $N$ samples, respectively, showing that the cracks in $N$ interfaces propagate 30 times slower than those in virgin ones. In the $\mathrm{G}_{\max }$ range common at the two configurations the ratio among propagation rates spans from 36.4 to 27.2.

Having assessed the effectiveness of the nanointerlayer in retarding both crack initiation and propagation under Mode I static and fatigue loading, it is interesting to show how this study compares with others within this topic.

Daelemans et al. [35] tested CFRP specimens interleaved with PA6,6 and PA6,9 nanofibers, under static Mode I and Mode II loading conditions. They presented discordant results when using $18 \mathrm{~g} / \mathrm{m}^{2}$ nanofibrous veils: in particular they registered a reduction of $\mathrm{G}_{\mathrm{C}}$ and $\mathrm{G}_{\mathrm{R}}$ with PA6,6, and an increase with PA6,9. In the case of enhanced properties the authors claimed that the main reinforcing mechanism was the crack bridging. The improvements presented in this present paper are significantly higher because of the different reinforce mechanisms, discussed in $\S 3.3$.

Fazal et al. [36] showed that the nanofibrilmat is responsible for an interlaminar fracture toughness improvement of 255-322\%. Their nanointerlayers were thicker $(70-100$ vs. $40 \mu \mathrm{m})$ and their nanofibers had similar diameter (500 vs. 400-650 nm) compared to those used here.

Shivakumar [24] performed a deep investigation on Nylon 6,6 nanomodified UD laminates, showing increases of 150,30 and $67 \%$ increase of $\mathrm{G}_{\mathrm{C}}, \mathrm{G}_{\mathrm{R}}$ and $\mathrm{G}_{\mathrm{I}}$ at $10^{6}$ cycles, respectively by using nanofibers. In the present work, $\mathrm{G}_{\mathrm{C}}$ and $\mathrm{G}_{\mathrm{R}}$ are increased by 137 and $124 \%$, respectively; furthermore, we found that $\mathrm{G}_{\max }$ for $V$ and $N$ specimens at 215000 cycles is 182 and 343 $\mathrm{J} / \mathrm{m}^{2}$ respectively, with an increase of $88 \%$ when the nanofibers are applied, as visible in Figure $2 \mathrm{~b}$

The only work studying crack propagation of nanointerleaved composite laminates is [11]: authors use MWCNT as interleaving material to increase Mode I fracture toughness, and recorded a $\Delta \mathrm{G}$ in the range of $104 \div 313 \mathrm{~J} / \mathrm{m}^{2}$, and an increase in $\mathrm{G}_{\mathrm{R}}$ comparable to the result of this work. However, they noted a lower reduction of crack propagation rate (10 to 2 times vs. the 36.4 to 27.2 shown here) and also a 1-5\% increase in specimen's thickness, with the risk of reducing other mechanical properties of the laminate [37]. Furthermore, their study could not find clear evidence of the reinforcement mechanisms, which is instead shown in $\S 3.3$ and $\S 3.4$ of this study. 


\subsection{Micrography}

In the next section 50x photographs of the side of $V$ and $N$ specimens are shown and used to investigate crack paths.

Figure 5 shows the crack path in a virgin specimen.
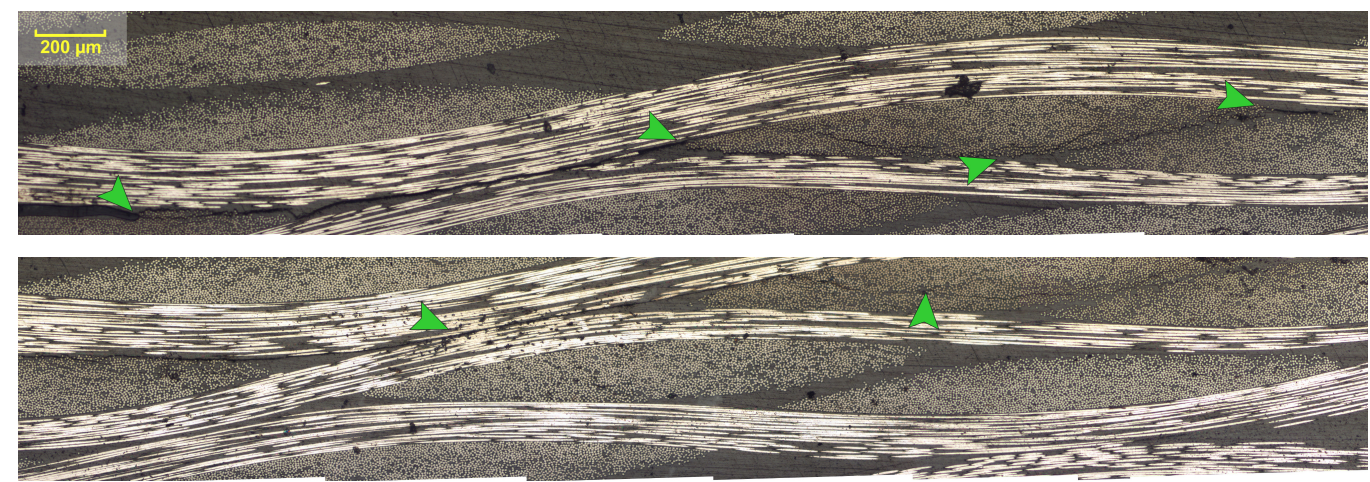

Figure 5: Crack path in a $V$ specimen. Read the figure from left to right, top to bottom

It is widely recognised that cracks do not move across plies in traditional laminates. Accordingly, the crack path in virgin specimens shown in Figure 5 , has been found to always propagate within the same interface.

Figure 6 shows a different scenario for nanomodified interfaces. 

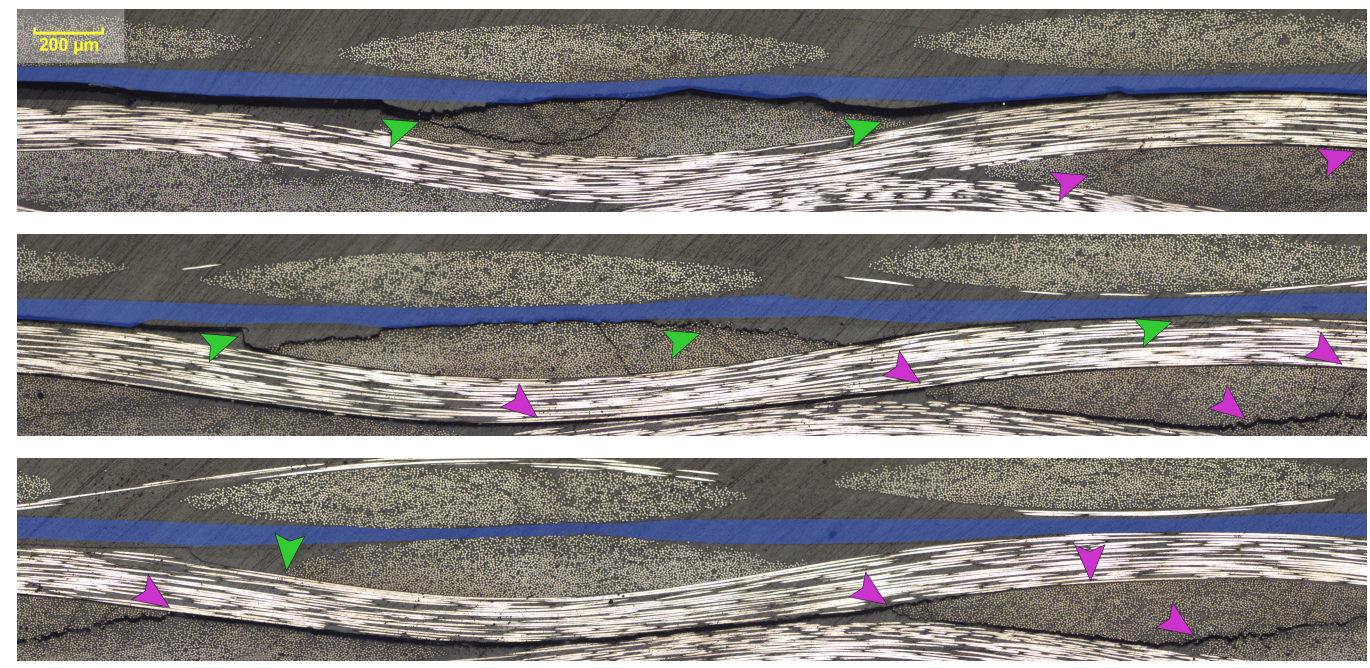

(a) Side view of the crack path. Read the figure from left to right, top to bottom.

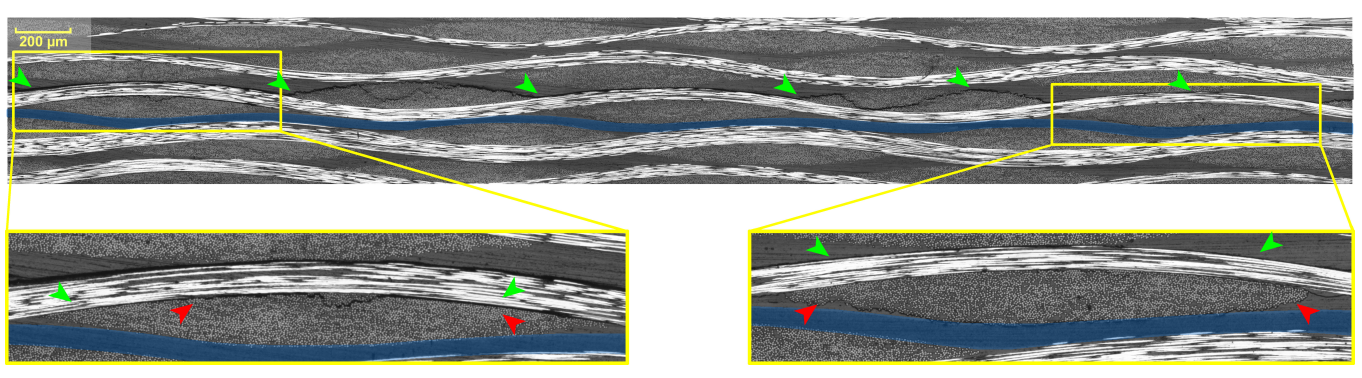

(b) Crack front.

Figure 6: Crack paths in $N$ specimen. The blue line indicates the location of the nanofibers

The micrographs suggest a double-stage reinforce mechanism:

- the image at the top of Figure 6a presents the first few millimetres of propagation, at the beginning of the test. At this stage, the crack (identified by green arrows) propagates in the same interface where it has been initiated, as expected, and the nanolayer keeps it confined in a narrow region, between the ply and the nanofibers. The right end of the first image shows that a second crack appears (identified by purple arrows). The nanofibers, reinforcing the interface, encourage the development of a second crack in a lower weaker layer not reinforced with nanofibers. The new crack is initially smaller and thinner compared to the main old one; the second image shows that the old cracks fades away while the new one grows larger. The last image shows that the 
original crack has arrested and the fracture has continued to propagate in a lower layer of the sample;

- The main image in Figure 6b shows a cross-section of the cracked sample: it can be observed that the crack front crosses the tow in several points, and has a complex morphology. Figure 6a itself could not explain why the fracture properties of the nanomodified samples increase once the crack propagates in a non-nanomodified interface; Figure 6b, instead, suggests that the crack crosses different planes at the same time through its width, involving the nanomodified toughened interface, as shown by the red arrows in the two zoomed particulars.

It can be concluded that at the early stage the crack is confined between the toughened nanomodified interlayer and the carbon fibers, bouncing up and down between the two, and requiring higher amount of energy to propagate compared to a $V$ interface; at a later stage, nanofibers force the crack to propagate in different planes, wide- and thick-wise, hindering the propagation of the fracture.

\subsection{Fracture surface analysis}

Figure 7 shows the fracture surfaces of the specimens, captured with a SEM at 3 different magnitudes: 300x, 1500x, and 3000x. 


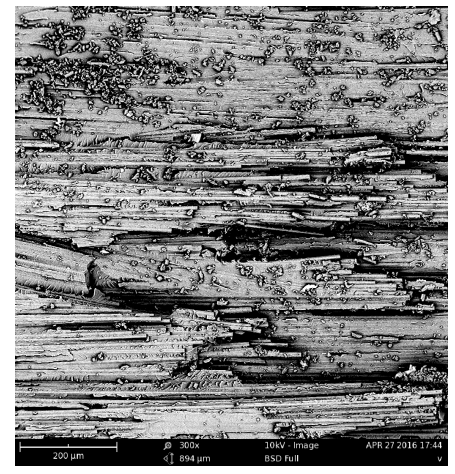

(a) $V$ interface at $300 \mathrm{x}$

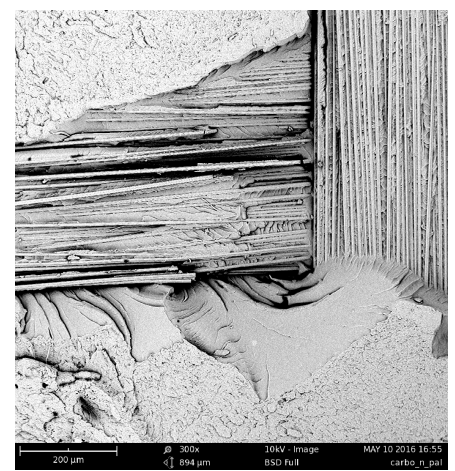

(d) $N$ interface at $300 \mathrm{x}$

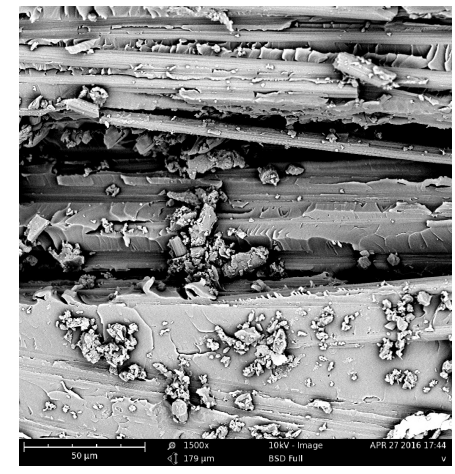

(b) $V$ interface at $1500 \mathrm{x}$

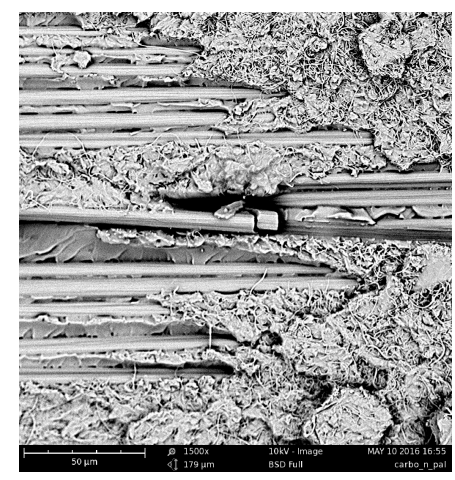

(e) $N$ interface at $1500 \mathrm{x}$

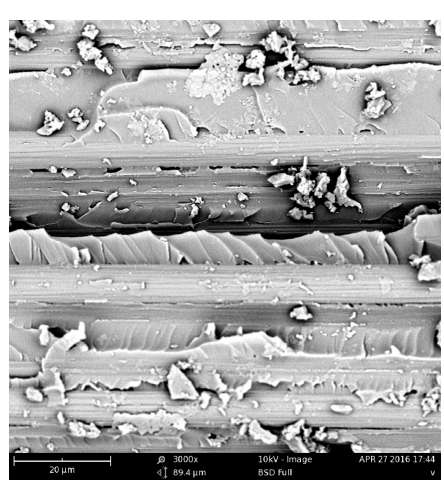

(c) $V$ interface at $3000 \mathrm{x}$

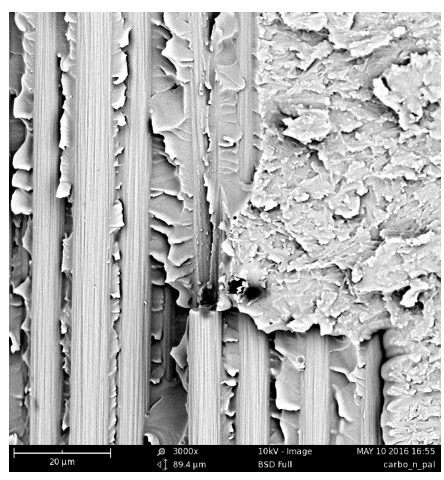

(f) $N$ interface at $3000 \mathrm{x}$

Figure 7: Fracture surfaces

SEM images provide evidences to support the thesis of the nanofiber toughening the interface. 300x pictures (Figure 7a and 7d) present a general view of the fracture surfaces: $V$ samples appear more brittle than their $N$ counterpart. Most importantly the images of $V$ shows a single fracture plane, as the crack propagates linearly in the very same interface. On the contrary the $N$ surface presents several fracture planes, as the fracture had to move up and down in order to find the path of minimum resistance, increasing the fracture surface and consequently also the energy spent to propagate.

At a higher magnitude (Figure $7 \mathrm{~b}$ and $7 \mathrm{e}$ ) nanofibers can be clearly seen. They keep the matrix consolidated, forcing the crack to propagate in the opposite direction.

At the highest magnitude, images (Figure 7c and 7f) show a broken carbon fiber in $N$ configuration and again multiple fracture planes.

SEM images confirmed the fracture mechanisms described above: nanofibers 
are able to toughen the matrix they are inserted within, hindering the crack propagation. Nanofibers holds the matrix together, avoiding the brittle fracture typical of a non-nanomodified interfaces, forcing the crack to propagate in non-reinforced interfaces.

\section{Conclusion}

Results of an experimental campaign on static and fatigue DCB tests on virgin and nanomodified composite laminate woven samples has been presented. This study aimed to assess the effectiveness of an electrospun mat interleaved within DCB specimens.

Static fracture tests revealed that nanomodified interfaces increase propagation fracture toughness of $124 \%$ compared to virgin samples, while fatigue tests, for a crack grow ratio of $5 \cdot 10^{-5} \mathrm{~mm} /$ cycle registered an improvement of $96 \%$.

Fatigue tests also showed that for values of $\mathrm{G}_{\max }$ in the considered range, the crack in a nanomodified interface propagates several times slower than in a virgin one. In other words, for a given crack propagation rate, nanomodified samples can withstand much higher loads.

Fractography showed that nanofibers act as matrix reinforcement and force the crack to propagate through different interfaces, causing a sensible increase of the energy needed to propagate.

SEM images showed that the nanofibers hold the matrix together whilst forcing the crack to move away from the nanomodified interface.

\section{References}

[1] N. Sela, O. Ishai, Interlaminar fracture toughness and toughening of laminated composite materials: a review, Composites 20 (5) (1989) 423435.

[2] I. Trendafilova, R. Palazzetti, A. Zucchelli, Damage assessment based on general signal correlation. Application for delamination diagnosis in composite structures, European Journal of Mechanics - A/Solids 49 (2015) 197-204.

[3] C. Marieta, E. Schulz, L. Irusta, N. Gabilondo, A. Tercjak, I. Mondragon, Evaluation of fiber surface treatment and toughening of thermoset matrix on the interfacial behaviour of carbon fiber-reinforced 
cyanate matrix composites, Composites Science and Technology 65 (14) (2005) 2189-2197.

[4] T. Yang, C. Wang, J. Zhang, S. He, A. Mouritz, Toughening and selfhealing of epoxy matrix laminates using mendable polymer stitching, Composites Science and Technology 72 (12) (2012) 1396-1401.

[5] E. Fuoss, P. Straznicky, C. Poon, Effects of stacking sequence on the impact resistance in composite laminates - Part 1: parametric study, Composite Structures 41 (1998) 67-77.

[6] A. Zhamu, Y. Hou, W. Zhong, J. Stone, J. Li, C. Lukehart, Properties of a Reactive-Graphitic-Carbon-Nanofibers-Reinforced Epoxy, Polymer Composites 28 (5) (2007) 605-611.

[7] W. Howard, T. Gossard, R. Jones, Composite laminate free-edge reinforcement with U-Shaped Caps. Part I: stress analysis, AIA Journal 27 (5) (1988) 610-616.

[8] I. Partridge, D. Cartié, Delamination resistant laminates by Z-Fiber pinning: Part I manufacture and fracture performance, Composites Part A: Applied Science and Manufacturing 36 (1) (2005) 55-64.

[9] G. Tang, Y. Yan, X. Chen, J. Zhang, B. Xu, Z. Feng, Dynamic damage and fracture mechanism of three-dimensional braided carbon fiber/epoxy resin composites, Materials \& Design 22 (2001) 21-25.

[10] D. Bortz, C. Merino, I. Martin-Gullon, Augmented fatigue performance and constant life diagrams of hierarchical carbon fiber/nanofiber epoxy composites, Composites Science and Technology 72 (3) (2012) 446-452.

[11] M. Arai, J. Hirokawa, Y. Hanamura, H. Ito, M. Hojo, M. Quaresimin, Characteristic of Mode I fatigue crack propagation of CFRP laminates toughened with CNF interlayer, Composites Part B: Engineering 65 (2014) 26-33.

[12] Y. Zhou, S. Jeelani, T. Lacy, Experimental study on the mechanical behavior of carbon/epoxy composites with a carbon nanofiber-modified matrix, Journal of Composite Materials 48 (29) (2014) 3659-3672. 
[13] J. Park, J. Jang, Z. Wang, D. Kwon, K. Devries, Self-sensing of carbon fiber/carbon nanofiber-epoxy composites with two different nanofiber aspect ratios investigated by electrical resistance and wettability measurements, Composites Part A: Applied Science and Manufacturing 41 (11) (2010) 1702-1711.

[14] I. Guseva Canu, T. Bateson, V. Bouvard, M. Debia, C. Dion, K. Savolainen, I. Yu, Human exposure to carbon-based fibrous nanomaterials: A review, International Journal of Hygiene and Environmental Health 219 (2) (2016) 166-175.

[15] H. Saghafi, R. Palazzetti, A. Zucchelli, G. Minak, Impact response of glass/epoxy laminate interleaved with nanofibrous mats, Engineering Solid Mechanics 1 (3) (2013) 85-90.

[16] T. Brugo, G. Minak, A. Zucchelli, H. Saghafi, M. Fotouhi, An Investigation on the Fatigue based Delamination of Woven Carbon-epoxy Composite Laminates Reinforced with Polyamide Nanofibers, Procedia Engineering 109 (2015) 65-72.

[17] H. Saghafi, S. Ghaffarian, T. Brugo, G. Minak, A. Zucchelli, H. Saghafi, The effect of nanofibrous membrane thickness on fracture behaviour of modified composite laminates - A numerical and experimental study, Composites Part B: Engineering 101 (2016) 116-123.

[18] L. Mazzocchetti, E. D’angelo, T. Benelli, J. Belcari, T. Brugo, A. Zucchelli, L. Giorgini, Poly- $\mathrm{m}$-aramid nanofiber mats: Production for application as structural modifiers in CFRP laminates, AIP Conference Proceedings 1736 (2016) Article number 4949591.

[19] N. Fallahi, G. Nardoni, H. Heidary, R. Palazzetti, X. Yan, A. Zucchelli, Supervised and Non-supervised AE Data Classification of Nanomodified CFRP During DCB Tests, FME Transaction 44 (4) (2016) 415-421.

[20] S. Alessi, M. di Filippo, C. Dispenza, M. Focarete, C. Gualandi, R. Palazzetti, G. Pitarresi, A. Zucchelli, Effects of Nylon 6,6 Nanofibrous Mats on Thermal Properties and Delamination Behavior of High Performance CFRP Laminates, Polymer Composites 36 (7) (2015) 13031313. 
[21] H. Saghafi, R. Palazzetti, A. Zucchelli, G. Minak, Influence of electrospun nanofibers on the interlaminar properties of unidirectional epoxy resin/glass fiber composite laminates, Journal of Reinforced Plastics and Composites 34 (11) (2015) 907-914.

[22] R. Palazzetti, X. Yan, A. Zucchelli, Influence of geometrical features of electrospun Nylon 6,6 interleave on the CFRP laminates mechanical properties, Polymer Composites 35 (1) (2014) 137-150.

[23] R. Palazzetti, Flexural behavior of carbon and glass fiber composite laminates reinforced with Nylon 6,6 electrospun nanofibers, Journal of Composite Materials 49 (27) (2015) 3407-3413.

[24] K. Shivakumar, S. Lingaiah, H. Chen, P. Akangah, G. Swaminathan, L. Russell, Polymer Nanofabric Interleaved Composite Laminates, AIAA Journal 47 (7) (2009) 1723-1729.

[25] T. Brugo, R. Palazzetti, The effect of thickness of Nylon 6,6 nanofibrous mat on Modes I-II fracture mechanics of UD and woven composite laminates, Composite Structures 154 (2016) 172-178.

[26] ASTM D5528-13, Standard Test Method for Mode I Interlaminar Fracture Toughness of Unidirectional Fiber-Reinforced Polymer Matrix Composites, Annual Book of ASTM Standards (2014) 1-13

[27] K. Shivakumar, H. Chen, F. Abali, D. Le, C. Davis, A total fatigue life model for mode I delaminated composite laminates, International Journal of Fatigue 28 (1) (2006) 33-42.

[28] M. Olave, I. Vara, H. Usabiaga, L. Aretxabaleta, S. Lomov, D. Vandepitte, Mode I fatigue fracture toughness of woven laminates: Nesting effect, Composite Structures 133 (2015) 226-234.

[29] ASTM D6115-97, Standard test method for mode I fatigue delamination growth onset of unidirectional fibre-reinforced polymer matrix composites, Annual Book of ASTM Standards 15.03 (Reapproved) (2001) 1-6.

[30] ASTM E647-15, Standard Test Method for Measurement of Fatigue Crack Growth Rates, Annual Book of ASTM Standards 
[31] J. Pascoe, R. Alderliesten, R. Benedictus, Methods for the prediction of fatigue delamination growth in composites and adhesive bonds A critical review, Engineering Fracture Mechanics 112-113 (2013) 72-96.

[32] N. Sato, M. Hojo, M. Nishikawa, Intralaminar fatigue crack growth properties of conventional and interlayer toughened CFRP laminate under mode I loading, Composites Part A: Applied Science and Manufacturing 68 (2015) 202-211.

[33] K. Kageyama, K. Kimpara, I. Osawa, M. Hojo, Damage tolerance estimation of advanced composite materials (1st report: Study on interlaminar fracture toughness test), Journal of the Society of Naval Architects of Japan 168 (1990) 497-506.

[34] P. C. Paris, M. P. Gomez, W. E. Anderson, A rational analytic theory of fatigue (1961).

[35] L. Daelemans, S. van der Heijden, I. De Baere, H. Rahier, W. Van Paepegem, K. De Clerck, Nanofibre bridging as a toughening mechanism in carbon/epoxy composite laminates interleaved with electrospun polyamide nanofibrous veils, Composites Science and Technology 117 (2015) 244-256.

[36] A. Fazal, K. Fancey, Mode I interlaminar fracture toughness of Nylon 66 nanofibrilmat interleaved carbon/epoxy laminates, Polymers and Polymer Composites 16 (2) (2008) 101-113.

[37] J. Zhang, T. Lin, X. Wang, Electrospun nanofibre toughened carbon/epoxy composites: Effects of polyetherketone cardo (PEK-C) nanofibre diameter and interlayer thickness, Composites Science and Technology 70 (11) (2010) 1660-1666.

[38] R. Palazzetti, A. Zucchelli, I. Trendafilova, The self-reinforcing effect of nylon 6,6 nano-fibres on CFRP laminates subjected to low velocity impact, Composite Structures 106 (2013) 661-671. 